\title{
ECOWAS and Civil Society \\ Movements in West Africa
}

\section{'Funmi Olonisakin}

Abstract This article argues that the West African subregion has radically shifted its approach to security from a state-centred framework to one that now encompasses human security concerns. Civil society is now an active part of the regional security decision-making processes. While it has been difficult to transform local-level civil society engagement into a large-scale regional involvement, civil society engagement with the Economic Community of West African States (ECOWAS) has nonetheless become more focused and effective. This article explains this transformation in the regional security agenda and ECOWAS-civil society collaboration, contending that the institutionalisation of the latter has had a mutually beneficial impact. It concludes with a discussion of the challenges that lie ahead for this relationship and the process of movement building.

\section{Introduction}

Notwithstanding a long history of authoritarian governance and instability created by more than a decade of violent conflict, West Africa has shifted its security focus from state security to include human security concerns. This shift comprises three relevant elements. First, the state is no longer the primary focus of security in the subregion. It has been difficult to ignore the root causes of major armed conflict since 1990, which demonstrate that the security of the state is underpinned by the security of its peoples. Second, the state is no longer the sole security actor or contributor to security decision-making processes. Rather, non-state security actors are more prominent with civil society playing an active role. Third and crucially, this pattern of active civil society involvement in security processes has been more noticeable at the subregional level than at the national level. This has been particularly visible in the interaction between the Commission of the Economic Community of West African States (ECOWAS) and civil society groups.

This article examines why and how the West African subregion has evolved a security framework that encompasses human security, not just state security, and includes civil society groups in regional security decision-making. It focuses mainly on the interaction between ECOWAS and West African civil society in the field of peace and security, ${ }^{1}$ arguing that the transformation in civil society engagement with ECOWAS from an ad hoc to a more institutionalised interaction has been a mutually strengthening process.

\section{ECOWAS's security thinking since the end of the Cold War}

ECOWAS, which was founded in 1975 for reasons of economic integration, radically changed course when it became saddled with the Liberian civil war in 1990 and later with the war in Sierra Leone in March 1991. Although these conflicts were not the first times that ECOWAS paid attention to security issues in the region, they presented a distinctly different set of security challenges. ${ }^{2}$ For much of the period between its inception in 1975 until 1990, ECOWAS viewed security only in terms of threats to the state. Typically, security crises occurring within the boundaries of a member state were deemed to be the domestic jurisdiction of that state. Thus, at the outbreak of the Liberian civil war in December 1989, there was not any expectation of a regional response.

The Liberian conflict was the first to reveal the scale of governance deficits in African states. 
West Africa was home to many authoritarian regimes, which were shored up by superpower allies during the Cold War and could no longer count on that support in a new dispensation. With new conditionality for external support (e.g. democracy and good governance), opposition groups and citizens were, for the first time in decades, able to demand accountability from their rulers. Some governments heeded the call, thus averting an escalation to violent conflict (in Mali and Benin). Others (Liberia) did not seem to understand the realities of the time, which resulted in the escalation of conflict and a challenge to the regime through armed force.

The governance crisis in Liberia was common to many countries in the region. This proved to be the case in Sierra Leone, where the types of structural factors that led to the collapse of the Liberian state were also present; Guinea-Bissau and Côte d'Ivoire saw outbreaks of violent conflict in 1998 and 2002, respectively. It was clear that the nature and conduct of the conflicts, which were internal in origin but regional in their impact, were more intense than at any time in post-independence Africa. Civilians were the focus of violence, and many victims themselves ended up becoming perpetrators of violence and atrocities.

ECOWAS responded to these challenges incrementally. First, it maintained a semblance of order in the war-ravaged countries with its Ceasefire Monitoring Group, ECOMOG (Olonisakin 2003). The intractable nature of the conflicts and their devastating regional impact later emphasised the need to explore factors at the root of armed conflict. ECOWAS sought to strengthen its normative framework in the field of peace and security. In 1993, ECOWAS revised its Treaty, signalling a departure from implicit endorsement of authoritarian rule. The revised Treaty emphasised democracy and the rule of law as a new framework within which the economic integration and development agenda would be pursued (ECOWAS 1993). This was followed in 1999 by the adoption of the ECOWAS Protocol relating to the Mechanism for Conflict Prevention, Management, Resolution, Peacekeeping and Security, commonly referred to as the 'Mechanism', which now forms the core of the ECOWAS peace and security architecture. The Mechanism emphasised early warning and mediation, peacebuilding, as well as peacekeeping (ECOWAS 1999), and its provisions resulted in the restructuring of the ECOWAS Secretariat (now ECOWAS Commission).

The Mechanism moved ECOWAS from its earlier ad hoc approach to collective security to a coherent and institutionalised framework for security cooperation in the subregion. In 2001, ECOWAS adopted the Protocol on Democracy and Good Governance, which supplemented the Mechanism and introduced peacebuilding as part of the effort to prevent further violent conflict and achieve stability in West Africa (ECOWAS 2001). In January 2008, ECOWAS adopted the Conflict Prevention Framework (ECPF), which consolidates existing frameworks for conflict prevention and management and outlines a plan for addressing the structural causes of conflict.

ECOWAS' experience of norm development in the area of peace and security was driven by the nature and impact of the armed conflicts in the subregion. The organisation is considered perhaps the most progressive in Africa from which its subregional counterparts, and indeed the African Union, have much to learn. However, this success in norm setting should also be viewed within the context of a major shift in position by the continental organisation. ECOWAS led the way in departing from strict adherence to the principles of non-interference in internal affairs of member states, particularly in situations of humanitarian tragedy. The Organisation of African Unity (now the African Union) later adopted a framework for addressing unconstitutional changes of government (Olonisakin 2007).

\section{Evolution of a civil society movement on peace and security}

A civil society movement in the field of peace and security is still evolving in West Africa. Civil society involvement in this field was neither prominent nor widespread in the subregion prior to 1990 amid the prevailing atmosphere of authoritarian governance. Discussion of security issues was the preserve of a chosen few, not least members of the security establishment. However, a new era, particularly one dominated by widespread violent intra-state conflict, has impacted West Africa's civilian population both negatively and positively. West African citizens have been the focus of violence but there are also increased opportunities for citizens to voice their 
demands for more open governance. Civil society is increasingly involved in the development of solutions to the security challenges that have impacted citizens' day-to-day existence.

Prominent security issues in civil society activism in West Africa include, for example, the impact of armed groups against civilian populations; the use, abuse and exploitation of children and women in situations of armed conflict; proliferation of small arms and light weapons and the role of security forces in citizens' lives. Civil society's focus on these issues is hardly surprising, given their centrality during the region's most devastating civil conflicts and authoritarian rule. In countries like Nigeria that did not experience the type of armed conflict in Liberia and Sierra Leone, the security establishment maintained a stranglehold on citizens' daily lives with various human rights violations. This inspired effective civil society campaigns against military rule in the 1990s until the sudden death of General Sanni Abacha in 1998 ended 15 years of military dictatorship. Similarly, Gambia has been under military authoritarian rule for the past 14 years, with rising incidents of human rights violations (Amnesty International 2008).

During the civil wars in Liberia, Sierra Leone, Côte d'Ivoire and, to a lesser degree, GuineaBissau, civilians became both victims and perpetrators. Children became weapons of war in ways that had not been previously seen in West Africa. The single highest incidence of childhood abduction occurred in Sierra Leone in January 1999 with the kidnapping of approximately 4,000 children by rebel forces during their invasion of Freetown. Similarly, forcing women to fight or subjecting them to rape as sexual slaves were common, particularly in Sierra Leone and Liberia. Such instances have compelled civil society to prevent similar recurrences of civil conflict.

Over time, West African civil society has developed various activities such as awareness campaigns, advocacy, policy and programmatic interventions. In different national contexts, civil society has provided the active, responsive voice to the security challenges impacting the daily lives of citizens. This advocacy has brought these issues to the global and regional security agenda, thus shifting the focus from traditional state security concerns.
A number of local civil society organisations and non-governmental organisations (NGOs) were founded to respond to some of these security concerns. These include, for example, Campaign for Good Governance (CGG) in Sierra Leone, Centre for Democratic Empowerment (CEDE), Catholic Justice and Peace Commission, and Foundation for International Integrity (FIND) in Liberia; Foundation for Security and Development in Africa (FOSDA), African Security Dialogue and Research (ASDR), and West African Network for Peacebuilding (WANEP) in Ghana; African Strategic and Peace Research Group (AFSTRAG), Centre for Democracy and Development (CDD) and CLEEN Foundation in Nigeria; RADHO in Senegal; the Mano River Women's Peace Network (MARWOPNET) in Guinea, Liberia and Sierra Leone; and the African Security Sector Network (ASSN), which extends beyond West Africa to the whole continent.

While individual citizens and local civil society groups are often at the frontline in responding to security issues, these issues have not automatically captured attention at the regional or global level. Other actors have provided the leverage to transform the issues and provide heightened visibility on a global stage.

International media has drawn significant attention to some of the most egregious violations of human rights including amputation of limbs, sexual exploitation and child soldiering. However, other actors, for example scholars and analysts in Africa and the Diaspora, international NGOs, international organisations and donor agencies have played a crucial role in up-scaling the work of local civil society actors. In addition, a number of regional policy decisions and processes such as the New Partnership for African Development (NEPAD) and the ECOWAS Moratorium on small arms provided opportunities for civil society action and engagement.

Activist and advocacy work in different West African countries has been backed by scholars and policy analysts in the region and abroad, albeit in varying degrees. This intellectual work has not only served to document abuses but also played a crucial role in challenging the sometimes inaccurate perceptions and assumptions about the West African security terrain (Vogt 1993; Vogt and Ekoko 1993). At times, it has also served to debunk the 
arguments of actors still stuck in the old security mindset, thus making a case for policy change. Similarly, such analysts have contributed to existing literature, for example, on Small Arms and Light Weapons (SALW) (Aning 2004; Ebo and Mazal 2003; Musah 2002), youth crisis (Rashid 2003) and security reform.

The mutual interdependence of local and global actors and processes is demonstrated by the way in which regional and global actors have shaped some of the human security issues of concern to West African peoples. Some issues have been given momentum in the last decade by various external actors and international processes. Three noteworthy issues include the impact of armed conflict on children, the proliferation of small arms and light weapons, and women's roles in peace and security. The global advocacy work of the Office of the UN Special Representative for Children and Armed Conflict led to engagement at both the national and regional levels in West Africa and lent momentum to advocacy work. International NGOs have provided support to local groups and, in some instances, have brought critical issues to the attention of the UN Security Council through Arria Formula meetings - a rare opportunity for direct engagement between non-state actors and members of the UN Security Council at a venue outside the Council Chamber.

Similarly, the West African Network on Small Arms (WAANSA) grew out of a global campaign against the proliferation of illicit arms, which was led largely by the International Network on Small Arms (IANSA). This global campaign in turn gained momentum as a result of the first global conference on Small Arms and Light Weapons at the UN in 2001, generating follow-up conferences. In the same vein, women's activism on peace and security issues in West Africa has been given added momentum by global processes, such as the Beijing Conference on Women in 1995, the resulting Platform for Action, and subsequent follow-up to the Beijing process.

However, despite increased civil society activism, heroism and outstanding leadership by select leaders in a number of national contexts, this has not necessarily translated into extensive civil society engagement on peace and security at the subregional level. Only a relatively small group of West African civil society actors have sustained the debate and consistently engaged with subregional actors on relevant issues.

Despite the quantity of those involved in peace and security work at the subregional level, it has been possible to stay engaged and make an impact for several reasons. First, this small meeting of minds is committed to peace and security in West Africa and has been operating as a loose network since the early 1990s. Second, the civil conflicts and continuing authoritarian rule in different national settings served to rally actors around similar issues, thus enabling them to consolidate and expand their network and areas of activity.

Several reasons explain the absence of a large civil society movement at the regional level. First is a weak knowledge base on peace and security issues. This is in part the result of a long period of exclusion of civilians from security discourse under authoritarian rule. Consequently, the role of civil society is often limited to activities such as protests and demonstrations, awareness campaigns and low-level advocacy work. Only a small number of civil society actors are able to provide intellectual leadership and engage with the discourse while conducting high-level advocacy. There is thus a tendency for a disconnection between those engaging policy-practitioners at regional and global levels and those operating at the frontline at the local level even if there is a consensus on the causes being advanced.

Second is a factor which compounds this disconnection, i.e. the tendency for national governments to become stumbling blocks to civil society work, especially when this might reveal a regime's governance deficits. A third and related factor is the absence of a systematic approach through training and leadership-building for a new generation of actors in this field. Much of the response is ad hoc as a result of certain young scholars and activists operating in isolation. Although programmes to address this gap are beginning to emerge, they are still too few to make a visible impact.

Finally, leadership of the small regional civil society movement is undergoing a transition. Many of the earlier generation of civil society leaders, who founded the organisations that have been at the forefront of the regional security debate, have themselves moved on to join governments or inter-governmental institutions. 
It is still too soon to see what this transition will mean for the regional work on peace and security, although it will be difficult to reverse some of the gains realised, not least because the now institutionalised engagement of these civil society leaders with ECOWAS.

\section{ECOWAS and civil society interaction}

In the fluid immediate post-Cold War environment, addressing West Africa's multifarious security concerns required innovation, creativity, and even gallantry, among a range of actors locally and regionally. Crucially, there was a critical mass of actors, which was instrumental in shaping the interaction between civil society and ECOWAS and helped create a credible formula for dealing with the exigency of the time.

Three main factors became apparent in civil society's effort to bring citizens' concern with security beyond immediate locales to national and regional levels. First, many national governments were not responsive to these security concerns, either because they did not have the capacity to respond or political will was lacking. Second, it was key officials of the central ECOWAS bureaucracy, the Commission, who demonstrated their willingness to work with civil society. Third, officials of some member states undergoing democratic transition were more open to civil society engagement with ECOWAS, sometimes facilitating civil society's access to ECOWAS processes.

Some West African states signed international conventions and agreements (e.g. on the protection of children) but failed to honour these conventions even if they were ratified. Thus, commitment to the conventions depended on the goodwill of individual governmental leaders.

Overall, many West African governments remained unreachable and impenetrable by civil society, authoritarian approaches being preferred even when a commitment was made to embark on democratic change. Although this is beginning to change, the staging of multi-party elections does not automatically translate into improved access to government by civil society.

Interestingly, while many West African governments were not accessible, civil society found ECOWAS a valuable entry point on a range of peace and security issues. At first glance, this appears contradictory because ECOWAS is governed by the decisions of Heads of State and Government; and one can imagine that leaders who are inaccessible to their population cannot effectively facilitate public access to a regional organisation where they are the key decision-makers. However, West African states were not all at the same level of recalcitrance. Some states had progressed further than others in their democratic transitions and openness to civil society engagement. States such as Ghana provided valuable entry points for regional civil society. Apart from this, the ECOWAS Commission has been more open to engagement with a range of actors, including bilateral and international agencies.

As ECOWAS developed its normative framework, its interaction with civil society became more visible. Since 2003, there has been a major shift in the nature and level of civil society and ECOWAS interaction. By then, a number of civil society organisations, including WANEP and CDD among others, had become active in ECOWAS consultations on peace and security. Gradually, these consultations began to coalesce into concrete initiatives that built upon ongoing work on peace and security in the region. Two events in January 2003 were significant not only in terms of consolidating civil society work on peace and security but also in strengthening ECOWAS-civil society collaboration.

The first was a meeting of civil society groups to review the UNDP supported Programme of Coordination and Assistance on Security and Development (PCASED), which was established to backstop the ECOWAS Moratorium on small arms and light weapons, adopted in 1998. Civil society gained access to the second event - the ECOWAS Ministerial meeting - largely with the support of the then Foreign Minister of Ghana, Hackman Owusu-Agyeman, who placed the issue on the agenda. Civil society's already ongoing engagement with ECOWAS made it possible to take the meeting's recommendations forward. ECOWAS's adoption in June 2006 of its Convention on Small Arms, Light Weapons, their Ammunition, and other Associated Material and the subsequent establishment of a Small Arms Unit in ECOWAS have been attributed, in part, to the influence of civil society. 
A relationship that was based on regular consultations moved rapidly toward institutionalisation. From 30 May to 1 June 2003, the ECOWAS Secretariat co-convened a consultation in Abuja with CDD and International Alert. This consultation focused on strengthening the capacity of ECOWAS and West African civil society on human security. Participants, including scholars, practitioners, civil society actors and funding agencies, analysed West Africa's human security situation according to the conditions in states experiencing conflict or emerging from conflict, states transitioning to stable democracy or consolidating democratically and states confronted with human security challenges. The consultation emphasised the need for collective regional response.

The conclusions set a framework for institutionalising this relationship, which included, among other things, the establishment of national and regional monitoring mechanisms on the status of human security; a review of the processes of civil society accreditation with ECOWAS; creation of a civil society unit in ECOWAS as well as an independent civil society secretariat to facilitate cooperation between West African civil society organisations and ECOWAS; and a West African Peoples' Assembly to coincide with the annual Summit of the Authority of Heads of State and Governments (ECOWAS, GDD and International Alert 2003).

In order to advance these proposals, an ad hoc group was established to work with the ECOWAS Commission, other ECOWAS institutions, the authorities of designated hoststates for ECOWAS Summit meetings and the peoples and civil society of West Africa. This group was given the task of developing appropriate contacts and partnerships to achieve these objectives.

The process of institutionalisation has progressed rapidly since this first meeting, resulting in the creation of a civil society unit. The West African Civil Society Forum (WACSOF) was formed before the end of 2003 and the first Peoples' Assembly was held prior to the Summit of Heads of State in December 2003. Representatives of civil society presented the outcome of the Assembly to the Heads of State meeting at that Summit, which has become an annual occurrence ever since. Unlike the period before 2000, it is now not unusual for civil society to be actively involved in ECOWAS initiatives and activities, including the Mechanism. For example, support for the ECOWAS Early Warning System has been developed in collaboration with WANEP. Similarly, the recently adopted ECOWAS Conflict Prevention Framework (ECPF) was developed with both ECOWAS and civil society expertise. Civil society is actively involved in the implementation of the ECPF Plan of Action.

This makes progress achieved so far difficult to reverse, even as the ECOWAS-civil society relationship continues to evolve.

Institutionalisation of the ECOWAS and civil society relationship marks a real shift in the way ECOWAS does business in addition to improving the responsiveness to security challenges on the ground. It will be difficult to alter even if future leadership in the ECOWAS Commission becomes less interested in collaborating with civil society. The present scale of interaction is already gradually reforming the ways in which West African leaders engage. Furthermore, it is clear that external partnerships have played a huge part in consolidating the ECOWAS-civil society relationship. Also, bilateral actors and international NGOs have supported collaboration through funding or policies. Indeed, such actors have sometimes relied on the advice of West African civil society actors in defining the terms of their own engagement with ECOWAS.

How can we best explain this rapid move toward institutionalisation of the ECOWAS-civil society interactions? The ECOWAS Mechanism and the subsequent restructuring of the Commission, which implies engagement with nongovernmental actors for an Early Warning System, offers one logical explanation. The requisite expertise for the analysis of particular security issues in the region resides within civil society. Thus it was inevitable that ECOWAS would need to rely on such expertise for the successful implementation of the Mechanism's provisions given the shortage of human resource capacity in the Commission. However, this might not have brought about considerable change in the way ECOWAS interacted with civil society because ECOWAS could have simply continued with an ad hoc arrangement, seeking expert support from civil society on a case-by-case basis. 
What transformed this relationship was the meeting of minds among leaders from the Commission and a group of security analysts and advocates within civil society. The inclination of the ECOWAS Executive Secretary (now President of the ECOWAS Commission), Dr Ibn Chambas, to engage with activists and analysts on the core security and development issues of concern was crucial. The former Deputy Executive Secretary for Political Affairs, Defence and Security, the late General Cheihk Oumar Diarra, was similarly inclined. It was therefore not difficult for civil society actors to gain access to ECOWAS. Most significantly, these developments coincided with Chambas's own strategic objective to form a closer working relationship between ECOWAS and civil society. Thus there was an open door at the highest level in the ECOWAS Commission for civil society engagement.

However, many challenges lie ahead for this new, evolving relationship. First, openness at the highest level in the ECOWAS Commission may not always be present, particularly after the expiry of the term of office of the present leadership. Second, even now, there is potential for friction as ECOWAS officials tend to see West African civil society through WACSOF, as natural allies, and expects that both will assume the same line of action on major political and security developments. In reality, they may sometimes disagree on approaches towards subregional or continental concerns (e.g. Zimbabwe).

Third, the still evolving civil society movement on peace and security faces the challenge of sustainability. Many of the movement's original leaders have transitioned into other roles in government or international organisations. It is

\section{Notes}

1 This article relies heavily on my observation of and direct participation in the process of crafting a West African civil society-ECOWAS agenda in response to the human security challenges in West Africa. too soon to see whether and how the next generation of leaders will advance their cause. Furthermore, the knowledge base on peace and security in the subregion remains weak, and much will depend on the degree to which it is strengthened by future West African scholars, policy analysts and activists.

Finally, the nature of civil society leadership will determine the degree to which external actors hijack the security agenda in the subregion. While Western donor countries and agencies continue to support the ECOWAS peace and security architecture, they remain uncoordinated in this approach with each sometimes promoting their own individual agendas. Only clarity of vision within ECOWAS and a dynamic civil society can curtail this tendency in the long run.

\section{Conclusion}

The same historical process that compelled ECOWAS to alter its course also opened up space for civil society activism and an emerging movement in the field of peace and security. The interaction between ECOWAS and West African civil society on issues of peace and security has no doubt been mutually beneficial. ECOWAS has expanded its terrain of activity and its knowledge base, and civil society has consolidated its work while successfully placing some of its security concerns on the agenda of the organisation. Together, both sides have been able to collaborate on an approach to security, which is moving the region from its exclusive focus on state security, to the security needs of its peoples. However, this relationship continues to evolve and will require sustained engagement in order to ensure an effective response to regional security challenges.

2 ECOWAS had adopted the Protocol on NonAggression in 1978, which focused on peaceful management of conflict between states. And in 1981, it adopted the Protocol on Mutual Assistance in Defence to address threats from outside the region. 


\section{References}

Amnesty International (2008) Gambia: Fear Rules, London: Amnesty International

Aning, Kwesi (2004) 'Moratorium on Small Arms and Light Weapons', African Security Review 13.3

Ebo, Adedeji and Mazal, Laura (2003) Small Arms Control in West Africa, London: International Alert

ECOWAS, CDD and International Alert (2003) Communique of the First ECOWAS Civil Society Consultation, Abuja CDD, 1 June

ECOWAS (2001) Protocol on Democracy and Good Governance, Dakar: ECOWAS, 21 December

ECOWAS (1999) Protocol Relating to the Mechanism for Conflict Prevention, Management, Resolution, Peacekeeping and Security, Lomé: ECOWAS, 10 December

ECOWAS (1993) Revised Treaty, Cotonou: ECOWAS, 24 July

Musah, Abdel-Fatau (2002) 'Small Arms, A Time Bomb Under West Africa's Democratizing Process', Brown Journal of World Affairs, Spring

Olonisakin, 'Funmi (2007) 'Pan African Approaches to Civilian Control and
Democratic Governance', in Victor-Yves Ghebali and Alexander Lambert (eds), Democratic Governance of the Security Sector Beyond the OSCE Area, Berlin: Lit Verlag

Olonisakin, 'Funmi (2003) 'ECOMOG Forces in Sierra Leone', in Ibrahim Abdullah (ed.), Between Democracy and Terror: The Sierra Leone Civil War, Dakar: CODESRIA

Rashid, Ismail (2003) 'Student Radicals, Lumpen Youth, and the Origins of the Revolutionary Groups in Sierra Leone, 1977-1996', in Abdullah Ibrahim (ed.), Between Democracy and Terror: The Sierra Leone Civil War, Dakar: Council for the Development of Social Science Research in Africa (CODESRIA)

Vogt, Margaret (1993) The Liberian Crisis and ECOMOG: A Bold Attempt at Regional Peacekeeping, Lagos: Gabumo

Vogt, Margaret and Ekoko, A.E. (eds) (1993) Nigeria in International Peacekeeping 1960-1992, Lagos and Oxford: Malthouse Press 